\title{
A NOTE ON SUMS OF POWERS
}

\author{
PENG GAO
}

Abstract. We improve a result of Bennett concerning certain sequences involving sums of powers of positive integers.

Mathematics subject classification (2010): 26D15.

Keywords and phrases: Majorization principle, sums of powers.

\section{REFERENCES}

[1] H. Alzer, On an inequality of H. Minc and L. Sathre, J. Math. Anal. Appl., 179 (1993), 396-402.

[2] H. AlZER, Refinement of an inequality of G. Bennett, Discrete Math., 135 (1994), 39-46.

[3] E. F. Beckenbach And R. Bellman, Inequalities, Springer-Verlag, Berlin-Göttingen-Heidelberg, 1961.

[4] G. Bennett, Lower bounds for matrices. II., Canad. J. Math., 44 (1992), 54-74.

[5] G. BENnetT, Sums of powers and the meaning of $l^{p}$, Houston J. Math., 32 (2006), 801-831.

[6] G. Bennett, Meaningful sequences, Houston J. Math., 33 (2007), 555-580.

[7] P. GAO, A note on Hardy-type inequalities, Proc. Amer. Math. Soc., 133 (2005), 1977-1984.

[8] P. GaO, Sums of powers and majorization, J. Math. Anal. Appl., 340 (2008), 1241-1248.

[9] A. W. Marshall AND I. OlKIn, Inequalities: theory of majorization and its applications, Academic Press, New York, 1979.

[10] J. S. Martins, Arithmetic and geometric means, an application to Lorentz sequence spaces, Math. Nachr., 139 (1988), 281-288.

[11] Z. K. XU AND D. P. XU, A general form of Alzer's inequality, Comput. Math. Appl., 44 (2002), $365-373$. 